\title{
Situação epidemiológica da brucelose bovina no Estado de Mato Grosso
}

\author{
[Epidemiologic situation of bovine brucellosis in the State of Mato Grosso, Brazil] \\ R.L. Negreiros ${ }^{1}$, R.A. Dias ${ }^{1}$, F. Ferreira ${ }^{1}$, J.S. Ferreira Neto ${ }^{1}$, V.S.P. Gonçalves ${ }^{2}$, \\ M.C.P. Silva ${ }^{3}$, V.C.F. Figueiredo ${ }^{4}$, J.R. Lôbo ${ }^{4}$, J.Freitas ${ }^{4}$, M. Amaku ${ }^{1 *}$ \\ ${ }^{1}$ Faculdade de Medicina Veterinária e Zootecnia - USP \\ Av. Prof. Dr. Orlando Marques de Paiva, 87 \\ 05508-270 - São Paulo, SP \\ ${ }^{2}$ Faculdade de Agronomia e Medicina Veterinária - UnB - Brasília, DF \\ ${ }^{3}$ Instituto de Defesa Agropecuária do Estado de Mato Grosso - Cuiabá, MT \\ ${ }^{4}$ Departamento de Saúde Animal - SDA-MAPA - Brasília, DF
}

\begin{abstract}
RESUMO
Caracterizou-se a brucelose bovina em Mato Grosso por meio de um estudo transversal realizado em 2003 para auxiliar na implementação do Programa Nacional de Controle e Erradicação da Brucelose e Tuberculose. No Estado, estratificado em quatro circuitos pecuários, foram amostrados 13.684 animais, provenientes de 1.152 rebanhos. O protocolo de testes utilizado foi o da triagem com o teste do antígeno acidificado tamponado e os soros reagentes foram testados pelo 2-mercaptoetanol (ME) e concomitantemente retestados pelo teste de Rosa Bengala para resultado conclusivo. As prevalências de focos e de animais infectados foram: 41,2\% [38,0-44,4\%] e 10,2\% [7,4-13,1\%], respectivamente. Nos circuitos produtivos, as prevalências de focos foram 36,9\% [29,2-45,2\%], 27,2\% [22,8-32,1\%], 40,4\% $[38,8-46,2 \%]$ e $50,3 \%$ [44,5-56,1\%]; e as prevalências de animais 7,9\% [3,0-12,9\%], 4,1\% [2,8-5,4\%], $8,1 \%$ [5,2-11,1\%] e 15,3\% [9,2-21,3\%], respectivamente, para os circuitos 1, 2, 3 e 4 . Os fatores de risco (odds ratio, OR) associados à condição de foco no Estado foram: exploração de gado de corte $(\mathrm{OR}=1,8$ $[1,2-2,5])$, exploração mista $(\mathrm{OR}=1,8[1,2-2,7])$, número de fêmeas no rebanho de 11 a $50(\mathrm{OR}=4,8[1,1-$ $20,8])$, número de fêmeas no rebanho acima de $51(\mathrm{OR}=6,8[1,6-29,0])$, ocorrência de aborto $(\mathrm{OR}=1,7$ [1,3-2,2]). A brucelose está homogeneamente distribuída no Estado, o que permite uniformidade de medidas sanitárias. Adicionalmente, sugere-se a intensificação da vacinação de fêmeas para todo o Estado.
\end{abstract}

Palavras-chave: bovino, brucelose, prevalência, fatores de risco, Mato Grosso

\section{ABSTRACT}

A study to characterize bovine brucellosis in the State of Mato Grosso was carried out in 2003 in order to support the implementation of the National Program for the Control and Eradication of Bovine Brucellosis. The State was divided into four productive regions, and 13,684 bovines from 1,152 herds were sampled. The serum samples were screened for antibodies to Brucella spp. by the Rose-Bengal test (RBT) and all RBT-positive sera were re-tested by the 2-mercaptoethanol test (2-ME), and again by RBT for confirmation. The prevalence of infected herds and animals in the State of Mato Grosso were $41.2 \%$ [38.0-44.4\%] and 10.2\% [7.4-13.1\%], respectively. In the productive regions, the prevalence of infected herds were 36.9\% [29.2-45.2\%], 27.2\% [22.8-32.1\%], 40.4\% [38.8-46.2\%], and 50.3\% [44.5-56.1\%], respectively; and the prevalence of infected animals were 7.9\% [3.0-12.9\%], 4.1\% [2.8-5.4\%], 8.1\% [5.2-11.1\%], and 15.3\% [9.2-21.3\%], respectively, for regions 1, 2, 3, and 4. The risk factors (odds ratio, OR) associated with the presence of the infection in the State were: beef cattle farming $(O R=1.8$ [1.2-2.5]), mixed (beef and dairy) cattle farming (OR=1.8 [1.2-2.7]), farms with 11 to 50 females $(O R=4.8$ [1.1-20.8]), farms with more than 51 females $(O R=6.8$ [1.6-29.0]), and occurrence of abortion

Recebido em 27 de março de 2009

Aceito em 23 de setembro de 2009

* Autor para correspondência (corresponding author)

E-mail: amaku@vps.fmvz.usp.br 
$(O R=1.7$ [1.3-2.2]). Given that brucellosis is homogeneously distributed in the State, uniform sanitary measures might be adopted. As a homogeneous additional measure for the State, the intensification of female vaccination is suggested.

Keywords: cattle, brucellosis, prevalence, risk factors, Mato Grosso, Brazil

\section{INTRODUÇ̃̃O}

Localizado na Região Centro-Oeste do Brasil, o Estado de Mato Grosso é o terceiro em dimensão territorial, compreendendo $903.357,9 \mathrm{~km}^{2}$, distribuídos em 141 municípios e ocupando $10,6 \%$ do território nacional. Apresenta como principal atividade econômica a bovinocultura. O gado vacum foi introduzido na região do Pantanal após a chegada dos primeiros espanhóis ao Continente, a partir de 1535. É o estado com a maior população bovina de corte do Brasil, onde predomina a raça Nelore. Mato Grosso responde por $14,5 \%$ do total de bovinos abatidos no Brasil (IBGE, 2007).

Após ser desmembrado para formar o atual Estado de Mato Grosso e o Estado de Mato Grosso do Sul, em 1979, o Estado realizou o primeiro censo agropecuário em 1985 e contabilizou 6.507 .632 de bovinos. A população bovina em 2006 era de 26.172.468 de cabeças, distribuídas em 105.997 propriedades rurais, de acordo com os dados cadastrais no Sistema Informatizado de Animais do Instituto de Defesa Agropecuária do Estado de Mato Grosso (Mato Grosso, 2006). As bacias hidrográficas dividem o Estado em três ecossistemas, favorecendo a distribuição dos rebanhos bovinos de forma diferenciada no Pantanal, Cerrado e região Amazônica. A região de Mata Amazônica e Florestas corresponde a $47,1 \%$ da área do Estado, o Cerrado a $44,0 \%$ e a região do Pantanal, a $8,8 \%$. As áreas norte, leste e nordeste do Estado drenadas pela Bacia Amazônica correspondem às regiões agropastoris do Estado (Mato Grosso, 2007).

O Pantanal, localizado a sudoeste do Estado e composto por seis municípios, é uma planície inundável regulada pela cheia (outubro a abril) e vazante (abril a outubro) da bacia do Rio Paraguai. De acordo com o Anuário 2006 (Mato Grosso, 2007), o Pantanal mantém a presença do gado no período seco e conta atualmente com $2.377 .133(9,1 \%)$ cabeças de bovinos em 7.334 propriedades.
A região centro-sul, caracterizada pelo ecossistema cerrado, composta por 84 municípios, com tendência para produção de leite, concentra a maior população humana e o maior número de indústrias de processamento de leite. A população bovina é de 7.071.168 $(27,0 \%)$ de cabeças, distribuídas em 22.505 propriedades.

As regiões norte, noroeste e nordeste do Estado são compostas por 51 municípios amazônicos. As duas primeiras caracterizam-se pela criação bovina de ciclo completo e a terceira, pela cria/engorda. Abrigam 16.724.277 (63,9\%) da população bovina do Estado, distribuídos em 75.578 propriedades. Em 2006 foram comercializados 5.104 .176 bovinos, sendo $33,9 \%$ para abate, $37,3 \%$ para engorda, $28,1 \%$ para reprodução, $0,11 \%$ para exposição e $0,63 \%$ para leilão.

O último diagnóstico nacional de situação da brucelose bovina foi realizado em 1975, e a estimativa da porcentagem de animais soropositivos foi $6,8 \%$ na região Centro-Oeste. Naquela ocasião, o Estado de Mato Grosso não havia sido dividido e os resultados dessa análise compreendiam uma amostra para toda a área que hoje corresponde aos dois Estados.

A partir de 1971, implementou-se no Estado o Serviço de Defesa Sanitária Animal. Com a divisão, o Estado de Mato Grosso firmou um convênio com o Ministério da Agricultura, visando combater a brucelose entre outras doenças de importância na bovinocultura.

O presente estudo teve como objetivo estimar a prevalência de focos e de animais soropositivos, identificar os fatores de risco para brucelose bovina no Estado e fornecer subsídios para a melhor implantação e gestão do Programa Nacional de Controle e Erradicação de Brucelose e Tuberculose (PNCEBT). 


\section{MATERIAL E MÉTODOS}

O estudo foi planejado por técnicos do Ministério da Agricultura, Pecuária e Abastecimento, da Universidade de São Paulo e da Universidade de Brasília, em colaboração com os técnicos do Instituo de Defesa Agropecuária do Estado de Mato Grosso (INDEA-MT). O trabalho de campo foi realizado por técnicos do INDEA-MT, no período de setembro de 2002 a dezembro de 2003.

Para que fossem conhecidas as diferenças regionais nos parâmetros epidemiológicos da brucelose bovina, o Estado de Mato Grosso foi dividido em quatro circuitos produtores de bovinos, levando em consideração os diferentes sistemas de produção, práticas de manejo, finalidades de exploração, tamanho médio de rebanhos e sistemas de comercialização. A divisão do Estado em regiões correspondentes a circuitos produtores também levou em conta a capacidade operacional e logística do serviço veterinário oficial do Estado para a realização das atividades de campo, baseando-se nas áreas de atuação das suas unidades regionais.

Em cada circuito produtor, estimou-se a prevalência de propriedades infectadas pela brucelose bovina e a de animais soropositivos por meio de um estudo amostral em dois estágios, dirigido para detectar focos da doença. No primeiro estágio, sorteou-se, aleatoriamente, um número pré-estabelecido de propriedades com atividade reprodutiva (unidades primárias de amostragem). No segundo, sorteou-se um número pré-estabelecido de fêmeas bovinas com idade igual ou superior a 24 meses (unidades secundárias de amostragem).

Nas propriedades rurais onde existia mais de um rebanho, foi escolhido o rebanho bovino de maior importância econômica, no qual os animais estavam submetidos ao mesmo manejo, ou seja, sob os mesmos fatores de risco. A escolha da unidade primária de amostragem foi aleatória, baseada no cadastro de propriedades rurais com atividade reprodutiva de bovinos. A propriedade sorteada que, por motivos vários, não pôde ser visitada, foi substituída por outra, nas proximidades e com as mesmas características de produção. $\mathrm{O}$ número de propriedades selecionadas por circuito foi estimado pela fórmula para amostras simples aleatórias (Thrusfield, 2007). Os parâmetros adotados para o cálculo foram: nível de confiança de 0,95 , prevalência estimada de 0,25 e erro de 0,05. A capacidade operacional e financeira do serviço veterinário oficial do Estado também foi levada em consideração para a determinação do tamanho da amostra por circuito.

O planejamento amostral para as unidades secundárias visou estimar um número mínimo de animais a serem examinados dentro de cada propriedade de forma a permitir a sua classificação como foco ou não foco de brucelose. Para tanto, foi utilizado o conceito de sensibilidade e especificidade agregadas (Dohoo et al., 2003). Para efeito dos cálculos foram adotados os valores de $95 \%$ e $99,5 \%$, respectivamente, para a sensibilidade e a especificidade do protocolo de testes utilizado (Fletcher et al., 1988) e 20\% para a prevalência estimada. Nesse processo foi utilizado o programa Herdacc versão 3, e o tamanho da amostra escolhido foi aquele que permitiu valores de sensibilidade e especificidade de rebanho iguais ou superiores a 90\%. Assim, nas propriedades com até 99 fêmeas com idade superior a 24 meses, foram amostrados 10 animais e nas com 100 ou mais fêmeas com idade superior a 24 meses, 15 animais. A escolha das fêmeas dentro das propriedades foi casual sistemática.

O protocolo do sorodiagnóstico foi composto pela triagem com o teste do antígeno acidificado tamponado (Rosa Bengala), seguida do reteste dos positivos com o teste do 2-mercaptoetanol, de acordo com as recomendações do PNCEBT (Brasil, 2006). O sangue foi coletado por punção da veia jugular com agulha descartável estéril em tubo com vácuo, previamente identificado. Os soros, armazenados em microtubos de plástico, foram mantidos a $-20^{\circ} \mathrm{C}$ até a realização dos testes. Os testes sorológicos foram realizados no Laboratório de Apoio à Saúde Animal do INDEA-MT.

A propriedade foi considerada positiva quando se detectou pelo menos um animal positivo. As propriedades que apresentaram animais com resultado sorológico inconclusivo, sem nenhum positivo, foram classificadas como suspeitas e excluídas das análises. O mesmo tratamento foi 
dado aos animais com resultados sorológicos inconclusivos.

O planejamento amostral permitiu determinar as prevalências de focos e de fêmeas adultas $(\geq 24 \mathrm{~m})$ soropositivas para brucelose no Estado e também nos circuitos produtores. Os cálculos das prevalências aparentes e os respectivos intervalos de confiança foram realizados conforme preconizado por Dean et al. (1994). Os cálculos das prevalências de focos e de animais no Estado, e de prevalências de animais dentro das

$P_{2}=\frac{\text { fêmeas } \geq 24 \text { meses na propriedade }}{\text { fêmeas } \geq 24 \text { meses amostradas na propriedade }} \times$

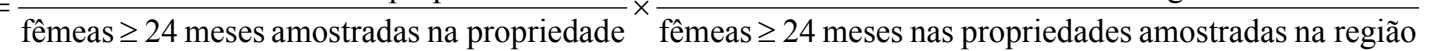

$\mathrm{Na}$ expressão acima, o primeiro termo refere-se ao peso de cada animal no cálculo das prevalências de animais dentro das regiões.

Em cada propriedade amostrada, além da coleta de sangue para a sorologia, foi também aplicado um questionário epidemiológico, elaborado para obter informações sobre o tipo de exploração e as práticas de manejo empregadas.

As variáveis analisadas foram: tipo ou sistema de exploração (carne, leite e misto), tipo de criação (confinado, semiconfinado, extensivo), uso de inseminação artificial, raças predominantes, número de vacas com idade superior a 24 meses, número de bovinos na propriedade, presença de outras espécies domésticas, presença de animais silvestres, destino da placenta e dos fetos abortados, compra e venda de animais, vacinação contra brucelose, abate de animais na propriedade, aluguel de pastos, pastos comuns com outras propriedades, pastos alagados, piquete de parição e assistência veterinária.

As variáveis foram organizadas de modo a apresentarem-se em escala crescente de risco. Quando necessário, realizou-se a recategorização dessas variáveis. A categoria de menor risco foi considerada como base para a comparação das demais categorias. As variáveis quantitativas foram recategorizadas em percentis. regiões foram feitos de forma ponderada (Dohoo et al., 2003).

$\mathrm{O}$ peso de cada propriedade no cálculo da prevalência de focos no Estado foi dado por

$$
P_{1}=\frac{\text { propriedades na região }}{\text { propriedades amostradasna região }}
$$

O peso de cada animal no cálculo da prevalência de animais no Estado foi dado por

\footnotetext{
fêmeas $\geq 24$ meses nas propriedades amostradas na região
}

Foi feita uma primeira análise exploratória dos dados (univariada) para seleção daquelas com $\mathrm{p} \leq 0,20$ para o teste do $\chi^{2}$ ou exato de Fisher e, subsequente, oferecimento dessas à regressão logística. Os cálculos foram realizados com o auxílio do programa SPSS, versão 9.0.

Todas as informações geradas pelo trabalho de campo e de laboratório foram inseridas em um banco de dados específico, utilizado nas análises epidemiológicas.

\section{RESULTADOS E DISCUSSÃO}

O Estado foi dividido em quatro circuitos (Fig. 1). No circuito 1 , cujo tipo de exploração é o de cria extensiva, optou-se por priorizar o ecossistema pantanal, com os fenômenos de vazante e cheia que o caracterizam. No circuito 2, caracterizado pelo ecossistema Cerrado, foram incluídos os municípios que apresentaram uma tendência para produção de leite. No circuito 3, foram incluídos os municípios com ciclo de engorda e o ecossistema amazônico, localizados em bacias hidrográficas do vale do Xingu, vale do Araguaia e limites com a Ilha do Bananal. No circuito 4 , foram incluídos os municípios com predominância para o sistema de cria. As informações censitárias do Estado estão organizadas na Tab. 1. 


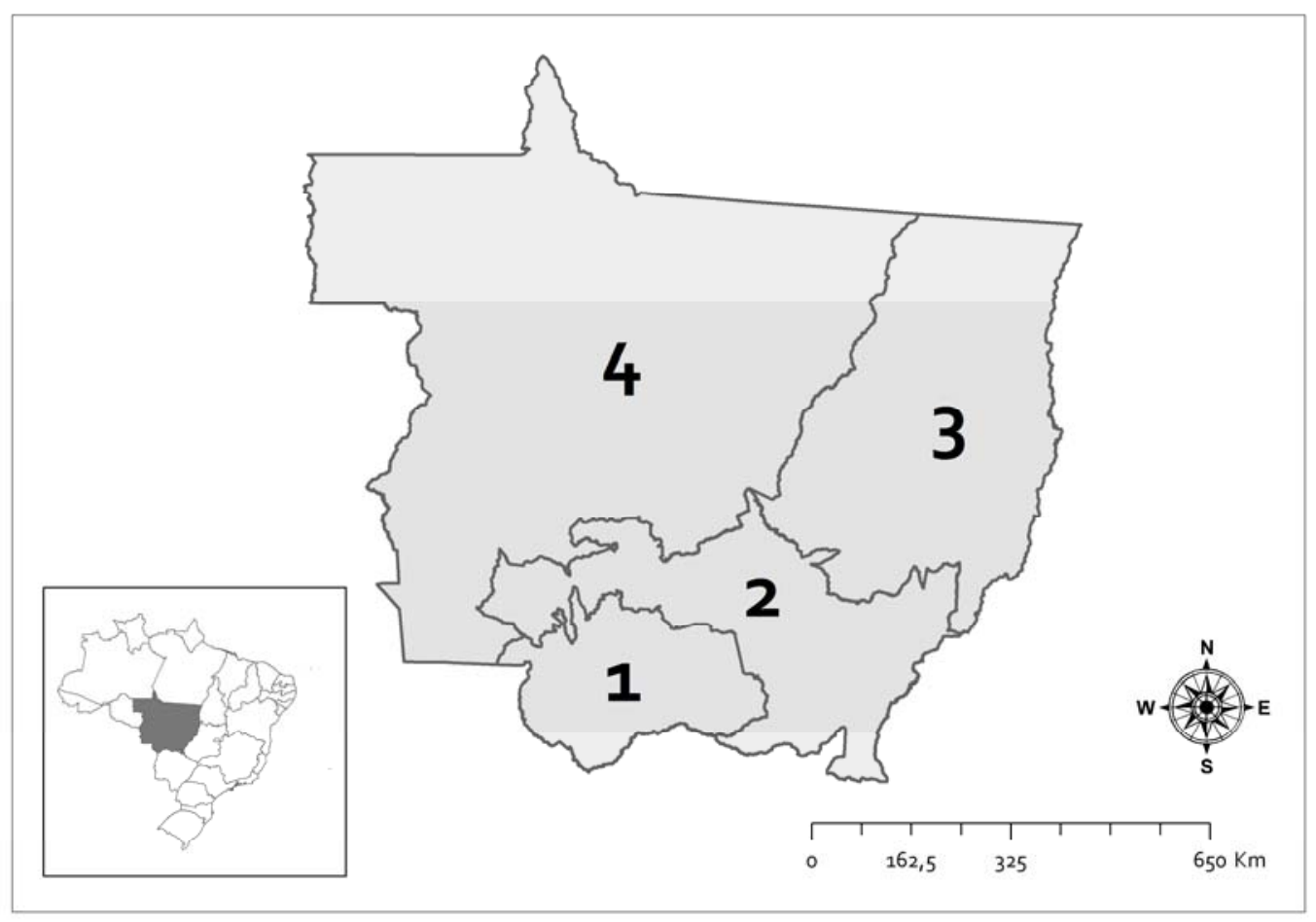

Figura 1. Mapa do Estado de Mato Grosso com a divisão em circuitos pecuários.

Tabela 1. Número de municípios, número total de propriedades e número de propriedades amostradas por circuito pecuário no Estado de Mato Grosso, 2002

\begin{tabular}{lccccc}
\hline $\begin{array}{c}\text { Circuito } \\
\text { pecuário }\end{array}$ & $\begin{array}{c}\mathrm{N}^{\mathrm{o}} \text { de } \\
\text { municípios }\end{array}$ & $\begin{array}{c}\text { Total de } \\
\text { propriedades } \\
\text { com atividade } \\
\text { reprodutiva }\end{array}$ & $\begin{array}{c}\text { Propriedades } \\
\text { amostradas }\end{array}$ & $\begin{array}{c}\text { Total de } \\
\text { fêmeas com } \\
\text { idade } \geq 24 \\
\text { meses }\end{array}$ & $\begin{array}{c}\text { Fêmeas } \\
\text { amostradas }\end{array}$ \\
\hline 1- Pantanal & 6 & 5.479 & 150 & 815.946 & 1.857 \\
2- Leite & 49 & 21.304 & 402 & 1.986 .726 & 4.692 \\
3- Engorda & 23 & 14.340 & 300 & 1.845 .746 & 3.676 \\
4- Cria & 53 & 41.351 & 300 & 3.729 .015 & 3.459 \\
Total & 131 & 82.474 & 1.152 & 8.377 .433 & 13.684 \\
\hline
\end{tabular}

As medianas para o número total de fêmeas foram $50,88,5$ e 191 para propriedades de leite, mistas e de corte, respectivamente. Foram amostrados 1152 rebanhos mas somente 1115 foram incluídos na análise. Dos 37 rebanhos excluídos, 34 apresentaram resultado final de teste inconclusivo e três eram rebanhos compostos exclusivamente por bubalinos.
$\mathrm{Na}$ Tab. 2, mostram-se os resultados da prevalência de focos no Estado e nos circuitos produtores. A Tab. 3 traz a prevalência de focos por tipo de exploração da propriedade e na Tab. 4 , a prevalência de animais. 
Tabela 2. Prevalência de focos para brucelose bovina no Estado de Mato Grosso, segundo o circuito produtor

\begin{tabular}{lcc} 
Circuito produtor & Prevalência (\%) & IC (95\%) \\
\hline 1- Pantanal & 36,9 & {$[29,2-45,2]$} \\
2- Leite & 27,2 & {$[22,8-32,1]$} \\
3- Engorda & 40,4 & {$[38,8-46,2]$} \\
4- Cria & 50,3 & {$[44,5-56,1]$} \\
Total & 41,2 & {$[38,0-44,4]$} \\
\hline
\end{tabular}

IC: intervalo de confiança.

Tabela 3. Prevalência (Prev) de focos de brucelose bovina estratificada por tipo de exploração, segundo o circuito produtor, no Estado de Mato Grosso

\begin{tabular}{|c|c|c|c|c|c|c|}
\hline \multirow{2}{*}{$\begin{array}{l}\text { Circuito } \\
\text { produtor }\end{array}$} & \multicolumn{2}{|c|}{ Corte } & \multicolumn{2}{|c|}{ Leite } & \multicolumn{2}{|c|}{ Misto } \\
\hline & Prev (\%) & IC (95\%) & Prev (\%) & IC $(95 \%)$ & Prev (\%) & IC $(95 \%)$ \\
\hline 1- Pantanal & 36,7 & {$[26,1-48,3]$} & 32,1 & {$[15,9-52,4]$} & 42,4 & {$[25,5-60,8]$} \\
\hline 2- Leite & 29,2 & {$[21,9-37,3]$} & 25,8 & {$[19,1-33,6]$} & 29,3 & {$[19,4-41,0]$} \\
\hline 3- Engorda & 44,2 & {$[37,5-51,1]$} & 15,0 & {$[3,2-37,9]$} & 28,3 & {$[17,5-41,4]$} \\
\hline 4- Cria & 53,8 & {$[46,0-61,4]$} & 26,7 & {$[16,1-39,7]$} & 65,2 & {$[52,4-76,5]$} \\
\hline
\end{tabular}

IC: intervalo de confiança.

Tabela 4. Prevalência de animais soropositivos para brucelose no Estado de Mato Grosso, segundo o circuito produtor

\begin{tabular}{lcc} 
Circuito produtor & Prevalência (\%) & IC (95\%) \\
\hline 1- Pantanal & 7,9 & {$[3,0-12,9]$} \\
2- Leite & 4,1 & {$[2,8-5,4]$} \\
3- Engorda & 8,1 & {$[5,2-11,1]$} \\
4- Cria & 15,3 & {$[9,2-21,3]$} \\
Total & 10,2 & {$[7,4-13,1]$} \\
\hline
\end{tabular}

IC: intervalo de confiança.

$\mathrm{Na}$ Tab. 5, apresentam-se os resultados da análise univariada e na Tab. 6, o modelo final da regressão logística.

O presente estudo foi direcionado para estimar a prevalência de focos de brucelose, tendo sido observada a seguinte ordem crescente de prevalência: o circuito pecuário $2, \quad$ cuja predominância é gado leiteiro, apresentou a menor prevalência estimada $(27,2 \%)$, seguido pelo circuito pecuário $1(36,9 \%)$, circuito pecuário $3(40,4 \%)$ e, por último, circuito pecuário $4(50,3 \%)$. Em uma comparação feita com base no intervalo de confiança de $95 \%$, a prevalência estimada no circuito 2 é menor que as observadas nos circuitos 3 e 4. Para o Estado de Mato Grosso, a prevalência estimada foi de $41,2 \%$ [38,0-44,4\%].

As estimativas de prevalência de foco de brucelose no Estado por tipo de exploração foram compatíveis, dentro do intervalo de confiança de $95 \%$, para os circuitos produtores 1,2 e 3 . No circuito 4 , a prevalência nas propriedades de leite foi menor que a observada nas propriedades de exploração mista. Esse resultado pode estar relacionado à aplicação da Portaria Ministerial 23 que regulamentou o trânsito interestadual com exigência de testes negativos para brucelose ou vacinação de bezerras das raças com aptidão leiteira, com idade entre três e oito meses (Brasil, 1976). 
Tabela 5. Porcentagem de positivos e negativos e resultados da análise univariada dos possíveis fatores de risco para brucelose no Estado de Mato Grosso, 2003, para variáveis com $\mathrm{p} \leq 0,20$

\begin{tabular}{|c|c|c|c|c|c|}
\hline Variável e categorias & $\mathrm{Neg}$ & Pos & Total & $\chi^{2}$ & $\mathrm{p}$ \\
\hline Vacina contra brucelose & & & & 49,8 & $<0,001$ \\
\hline $\operatorname{Sim}^{\mathrm{a}}$ & 168 & 191 & 359 & & \\
\hline Não & 520 & 236 & 756 & & \\
\hline Raça bovina predominante & & & & 41,2 & $<0,001$ \\
\hline $\mathrm{Zebu}^{\mathrm{a}}$ & 407 & 328 & 735 & & \\
\hline Europeu & 54 & 27 & 81 & & \\
\hline Mestiço/Outras raças & 206 & 60 & 266 & & \\
\hline Abate dos descartes & & & & 31,7 & $<0,001$ \\
\hline Não Abate & 247 & 87 & 334 & & \\
\hline Inspecionado & 207 & 174 & 381 & & \\
\hline Não Inspecionado & 234 & 166 & 400 & & \\
\hline Ocorrência de aborto & & & & 27,3 & $<0,001$ \\
\hline Não ${ }^{a}$ & 451 & 214 & 665 & & \\
\hline Sim & 203 & 190 & 393 & & \\
\hline Número total de fêmeas & & & & 25,4 & $<0,001$ \\
\hline$\leq 10$ fêmeas & 27 & 3 & 30 & & \\
\hline 11 a 50 fêmeas & 190 & 78 & 268 & & \\
\hline$\geq 51$ fêmeas & 471 & 346 & 817 & & \\
\hline Tipo de exploração & & & & 25,1 & $<0,001$ \\
\hline Leite $^{\mathrm{a}}$ & 194 & 65 & 259 & & \\
\hline Mista & 137 & 97 & 234 & & \\
\hline Corte & 350 & 261 & 611 & & \\
\hline Destino do aborto & & & & 23,0 & $<0,001$ \\
\hline Não faz nada ${ }^{a}$ & 542 & 281 & 823 & & \\
\hline Alimenta porco/cão & 11 & 12 & 23 & & \\
\hline Destino correto & 135 & 134 & 269 & & \\
\hline Piquetes para parto e/ou pós-parto & & & & 14,3 & $<0,001$ \\
\hline $\mathrm{Não}^{\mathrm{a}}$ & 375 & 183 & 558 & & \\
\hline Sim & 313 & 244 & 557 & & \\
\hline Realizam teste de brucelose & & & & 14,1 & $<0,001$ \\
\hline Não ${ }^{a}$ & 541 & 292 & 833 & & \\
\hline Sim & 147 & 135 & 282 & & \\
\hline Vende em leilão/feira & & & & 12,5 & $<0,001$ \\
\hline Não ${ }^{a}$ & 668 & 395 & 1.063 & & \\
\hline Sim & 20 & 32 & 52 & & \\
\hline Tipo de ordenha & & & & 14,3 & $<0,001$ \\
\hline Não ordenha ${ }^{a}$ & 255 & 202 & 452 & & \\
\hline Manual & 420 & 223 & 643 & & \\
\hline Mecânica/ou sala de ordenha & 13 & 2 & 15 & & \\
\hline $\mathrm{N}^{\mathrm{o}}$ de ordenhas ao dia & & & & 13,1 & 0,0014 \\
\hline Não ordenha ${ }^{a}$ & 262 & 203 & 465 & & \\
\hline $1 \mathrm{vez}$ ao dia & 403 & 219 & 622 & & \\
\hline 2 ou 3 vezes ao dia & 23 & 5 & 28 & & \\
\hline Compra de comerciante & & & & 3,9 & 0,005 \\
\hline Não ${ }^{a}$ & 636 & 380 & 1.016 & & \\
\hline Sim & 52 & 47 & 99 & & \\
\hline Contato com capivaras & & & & 7,3 & 0,0081 \\
\hline $\mathrm{Não}^{\mathrm{a}}$ & 438 & 237 & 675 & & \\
\hline Sim & 250 & 190 & 440 & & \\
\hline
\end{tabular}




\begin{tabular}{|c|c|c|c|c|c|}
\hline Variável e categorias & Neg & Pos & Total & $\chi^{2}$ & $\mathrm{p}$ \\
\hline Tipo de assistência veterinária & & & & 6,9 & 0,0087 \\
\hline Cooperativa $^{\mathrm{a}}$ & 12 & 1 & 13 & & \\
\hline Particular & 112 & 91 & 203 & & \\
\hline Compra em leilão/feira & & & & 6,9 & 0,009 \\
\hline Não ${ }^{a}$ & 626 & 367 & 993 & & \\
\hline Sim & 62 & 60 & 122 & & \\
\hline Áreas alagadas & & & & 6,5 & 0,011 \\
\hline Não ${ }^{a}$ & 535 & 303 & 838 & & \\
\hline Sim & 153 & 124 & 277 & & \\
\hline Compra reprodutores. & & & & 5,5 & 0,018 \\
\hline Não ${ }^{a}$ & 265 & 134 & 399 & & \\
\hline Sim & 423 & 293 & 716 & & \\
\hline Tipo de inseminação & & & & 5,4 & 0,02 \\
\hline Não usa ${ }^{a}$ & 641 & 380 & 1.021 & & \\
\hline Inseminação + touro & 47 & 47 & 94 & & \\
\hline Vende em exposição & & & & 5,1 & 0,025 \\
\hline Não ${ }^{a}$ & 681 & 415 & 1.096 & & \\
\hline Sim & 7 & 12 & 19 & & \\
\hline Tipo de criação & & & & 5,0 & 0,08 \\
\hline Confinado $^{a}$ & 12 & 7 & 19 & & \\
\hline Semiconfinado & 52 & 18 & 70 & & \\
\hline Extensivo & 624 & 402 & 1.026 & & \\
\hline Compra em exposição & & & & 2,9 & 0,088 \\
\hline Não ${ }^{a}$ & 664 & 403 & 1.067 & & \\
\hline Sim & 24 & 24 & 48 & & \\
\hline Vende para reprodução & & & & 1,9 & 0,17 \\
\hline $\mathrm{Não}^{\mathrm{a}}$ & 511 & 301 & 812 & & \\
\hline Sim & 177 & 126 & 303 & & \\
\hline \multicolumn{6}{|l|}{ A quem entrega leite } \\
\hline Não entrega ${ }^{a}$ & 427 & 283 & 710 & 3,3 & 0,19 \\
\hline Cooperativa/ Laticínio & 217 & 113 & 330 & & \\
\hline Direto ao consumidor & 44 & 31 & 75 & & \\
\hline
\end{tabular}

${ }^{a}$ Categoria de referência.

Tabela 6. Resultado da análise de regressão logística múltipla de fatores de risco (odds ratio) para brucelose bovina no Estado de Mato Grosso

\begin{tabular}{|c|c|c|c|c|}
\hline Variável & Categoria & Odds ratio & IC $(95 \%)$ & $\mathrm{p}$ \\
\hline \multirow[t]{3}{*}{ Tipo de exploração } & Leite $^{\mathrm{a}}$ & & & \\
\hline & Mista & 1,8 & {$[1,2-2,7]$} & 0,003 \\
\hline & Corte & 1,8 & {$[1,2-2,5]$} & 0,001 \\
\hline \multirow[t]{3}{*}{$\mathrm{N}^{\mathrm{o}}$ total de fêmeas } & Até 10 fêmeas ${ }^{\mathrm{a}}$ & & & \\
\hline & 11 a 50 fêmeas & 4,8 & {$[1,1-20,9]$} & 0,036 \\
\hline & 51 e mais fêmeas & 6,8 & {$[1,6-29,0]$} & 0,010 \\
\hline \multirow[t]{2}{*}{ Ocorrência de aborto } & Não ${ }^{a}$ & & & \\
\hline & Sim & 1,7 & {$[1,3-2,2]$} & $<0,001$ \\
\hline
\end{tabular}

${ }^{a}$ Categoria de referência. IC: intervalo de confiança. 
O último diagnóstico de situação de brucelose bovina realizado em 1975 estimou a porcentagem de animais soropositivos no Estado de Mato Grosso em 6,2\% (Paulin e Ferreira Neto, 2002). Os dados de notificações oficiais indicam que a prevalência de animais soropositivos para brucelose se manteve entre $4 \%$ e $5 \%$ no período de 1988 a 1998 . Com base nessas informações, a prevalência estimada de $10,2 \%$ [7,4-13,1\%] em animais, observada neste estudo, mostra aumento da enfermidade no Estado de Mato Grosso.

A prevalência estimada em animais apresentou a seguinte ordem crescente: $4,1 \%$ para o circuito pecuário $2,7,9 \%$ para o circuito pecuário $1,8,1 \%$ para o circuito pecuário 3 e $15,3 \%$ no circuito pecuário 4. Assim, a brucelose está presente em frequência elevada em todo o Estado, sendo recomendável tentar sua diminuição mediante vacinação de bezerras com a amostra B19.

O modelo final da regressão logística para o Estado indicou as variáveis exploração para corte $(\mathrm{OR}=1,8$ $[1,2-2,5])$, exploração mista $(\mathrm{OR}=1,8 \quad[1,2-2,7])$, propriedades com 11 a 50 fêmeas $(\mathrm{OR}=4,8[1,1-$ $20,8]$ ), propriedades com 51 ou mais fêmeas $(\mathrm{OR}=6,8 \quad[1,6-29,0])$ e ocorrência de aborto $(\mathrm{OR}=1,7[1,3-2,2])$ como associadas à condição de foco de brucelose bovina.

Os resultados mostraram que as propriedades com maior número de fêmeas apresentaram maior chance de ser foco de brucelose. A associação entre o tamanho do rebanho e a presença de brucelose foi demonstrada em vários estudos (Kellar et al., 1976; Nicoletti 1980; Salman et al., 1984). Nos grandes rebanhos não há diferenças individuais quanto à suscetibilidade à doença, mas algumas características desses grandes rebanhos podem facilitar a transmissão da brucelose, tais como: maior frequência de reposição de animais, maior quantidade de problemas relacionados ao controle sanitário e influência na dinâmica da doença (Crawford et al., 1990). Christie (1969) observou que o aumento do rebanho resulta em aumento da probabilidade de ocorrer a doença e de persistir a infecção, e aumento da prevalência da doença e da dificuldade de erradicá-la. Assim, número elevado de animais no rebanho significa maior risco de introdução da brucelose pela compra mais frequente de reprodutores. É importante enfatizar que a introdução de animais significa risco real apenas quando praticada sem cuidados sanitários. Nas propriedades de corte e mistas, o número de fêmeas é maior que nas de leite, medianas, respectivamente, de $191,88,5$ e 50 .
O histórico de aborto pode ser consequência da infecção brucélica, pois o abortamento é o principal sinal da doença na espécie bovina (Acha e Szyfres, 2001).

Recomenda-se concentrar esforços no programa de vacinação de $80 \%$ de fêmeas entre três e oito meses de idade com a vacina B19 e desencorajar a introdução de animais sem controle sanitário e qualquer modalidade de contato indireto entre propriedades.

\section{AGRADECIMENTOS}

À FAPESP, ao CNPq, ao INDEA-MT e ao MAPA pelo apoio financeiro.

\section{REFERÊNCIAS BIBLIOGRÁFICAS}

ACHA, P.N.; SZYFRES, B. Zoonosis y enfermedades transmisibles comunes al hombre y a los animales: Bacterioses e micoses 3.ed. Washington: OPAS, 2001. 416p.

BRASIL. Ministério de Agricultura, Pecuária e Abastecimento. Programa Nacional de Controle e Erradicação da Brucelose e da Tuberculose Animal (PNCEBT): Manual técnico. Brasília, 2006. 184p.

BRASIL. Ministério da Agricultura, do Abastecimento e da Reforma Agrária. Portaria no. 23/76, de 20 de janeiro de 1976: Manual de procedimentos. Movimentação interestadual de animais e produtos. 5.ed. Diário Oficial da União, Brasília, 16 de fev.1976. Seção I, pt. I, p.2266-2269.

CHRISTIE, T.E. Eradication of brucellosis in northern Ireland: Field problems and experiences. Vet. Rec., v.85, p.268-269, 1969.

CRAWFORD, R.P.; HUBER, J.D.; ADAMS, B.S. Epidemiology and surveillance. In: NIELSEN, K.; DUNCAN, J.R. (Ed.). Animal brucellosis. Boca Raton: CRC Press, 1990. p.131-151.

DEAN, A.G.; DEAN, J.A.; COLOMBIER, D. et al. Epi-Info, version 6: A word processing database and statistics program for epidemiology on microcomputers. Atlanta: CDC, 1994. 601p. 
DOHOO, I.; MARTIN, W.; STRYHN, H. Veterinary epidemiologic research. Charlottetown, Canadá: Atlantic Veterinary College, 2003. 706p.

FLETCHER, R.H.; FLETCHER, S.W.; WAGNER, E.H. Clinical epidemiology: The essentials. 2.ed. Baltimore: Williams \& Wilkins, 1998. 246p.

IBGE. Rio de Janeiro, 2007. Disponível em: $<$ http:www.sidra.ibge.gov.br>. Acessado em: 26 set. 2007.

KELLAR, J.; MARRA, R.; MARTIN, W. Brucellosis in Ontario: A case control study. Can. J. Comp. Med., v.40, p.119-128, 1976.

MATO GROSSO. Secretaria de Estado de Desenvolvimento Rural. Instituto de Defesa Agropecuária do Estado de Mato Grosso. Atividades de defesa sanitária animal com ênfase no estudo de área habilitada e não habilitada: Anuário 2006. Cuiabá, 2007. 174p.
MATO GROSSO. Instituto de Defesa Agropecuária do Estado de Mato Grosso. SIA ani2006. Cuiabá, 2006.

NICOLETTI, P. The epidemiology of bovine brucellosis. Adv. Vet. Sci. Comp. Med., v.24, p.69-98, 1980.

PAULIN, L.M.; FERREIRA NETO, J.S. A experiência brasileira no combate à brucelose bovina: Inst. Biol. São Paulo, v.69, p.105-112, 2002.

SALMAN, M.D.; MEYER, M.E.; HIRD, D. W. Epidemiology of bovine brucellosis in the Mexicali Valley, México: data gathering and survey results. Am. J. Vet. Res., v.45, p.15611566, 1984.

THRUSFIELD, M. Veterinary epidemiology. 3.ed. Oxford: Blackwell Science, 2007. 610p. 